

\title{
Pore Structure and Permeation Characteristics of Foamed Concrete
}

\author{
Ameer A. Hilal ${ }^{1 *}$, Nicholas H. Thom ${ }^{2}$ and Andrew R. Dawson ${ }^{3}$
}

\section{Abstract}

A study has been undertaken to investigate the pore structure characteristics, porosity and critical pore diameter of preformed foamed concrete with a density between 1300 and $1900 \mathrm{~kg} / \mathrm{m}^{3}$, and its effect on the permeation characteristics, water absorption and permeability. Different measured and calculated methods were adopted to determine the above properties and a comparison between them was done. Porosity was measured by apparent, total vacuum saturation and mercury intrusion porosimetry (MIP) methods, while permeability was measured (by constant and falling head methods) and calculated (by the Katz and Thompson model). Total porosity and dry density are found to be clearly related. The critical pore diameter (from the MIP test) and the pore diameter size $(>200 \mathrm{~nm})$ are found to be closely related to the permeability of foamed concrete.

\section{Introduction}

Foamed concrete is a versatile material consisting of either Portland cement paste or cement filler matrix (mortar), in which air voids are entrapped by a suitable foaming agent (Jitchaiyaphum et al. 2011; Nambiar and Ramamurthy 2007a; Othuman and Wang 2011; Ramamurthy et al. 2009). It would clearly be expected that the pore structure of foamed concrete has an important influence on its properties. These pores may be classified into gel pores, capillary pores and air voids (air entrained and entrapped pores) (Nambiar and Ramamurthy 2007a). In spite of their significant expected influence, the investigation and evaluation of the pore structure are seldom reported (Yu et al. 2011).

In a study undertaken to examine the moisture behaviour of clayey cellular concrete (Goual et al. 2006), three methods were applied to determine their porosity: mercury intrusion porosimetry, vacuum saturation and pycnometry. From a comparison of the total porosity values obtained, it was found that there is a high level of similarity.

The transport of aggressive liquids into concrete depends on its permeation characteristics such as permeability, water absorption and sorption (Nambiar and

${ }^{1}$ Lecturer, Civil Engineering Department, Faculty of Engineering, Univsersity of Anbar, Iraq, and $\mathrm{PhD}$ student, Department of Civil Engineering, Faculty of Engineering, University of Nottingham, Nottingham NG7 2RD, UK.

*Corresponding author, E-mail: evxaah@nottingham.ac.uk, ameer_amn@yahoo.com

${ }^{2}$ Lecture, Department of Civil Engineering, Faculty of Engineering, University of Nottingham, Nottingham NG7 2RD, UK.

${ }^{3}$ Associate Professor, Department of Civil Engineering, Faculty of Engineering, University of Nottingham, Nottingham NG7 2RD, UK.
Ramamurthy 2007b) which represent the most important factors affecting the service life of a concrete structure (Sanjuan and Munoz-Martialay 1996b). In consequence, an important indicator of concrete long term durability is its permeability which is the relative ease with which an aggressive substance can penetrate into concrete (Alshamsi and Imran 2002; Neville 2011; Sanjuan and Munoz-Martialay 1996b). The relationship between porosity and water vapour permeability was studied in foamed concrete and cement pastes by Kearsley and Wainwright (Kearsley and Wainwright 2001a). In this study, it was concluded that water vapour permeability increases with increased porosity, or decreased density, with similar trend lines for mixtures both with and without foam. The authors claimed that in the case of foamed concrete the air voids that are entrained can be considered as an aggregate and their inclusion might reduce the permeability not only by obstructing flow but also because of the absence of microcraking at the interface between air voids and the mortar. In a study of the pore structure of ordinary Portland cement paste, Cui and Cahyadi (2001), defined a critical pore diameter $\left(l_{c}\right)$ as the pore diameter above which a connected path could form throughout a sample and added that the smaller the $l_{\mathrm{c}}$, the finer the pore structure.

Yen (2007) listed some of the models used to predict the permeability of concrete as follows: the KozenyCarmen theory, the Katz-Thompson theory (developed for porous stone), statistical modelling, computer network model and composite model theory (also known as general effective media, GEM).

Cui and Cahyadi (2001) found that the difference in pore structure between stone and cement paste is due to the existence of gel pores in the latter. When the cement paste is very porous, capillary pores form a continuous network throughout the whole material. In this case and by ignoring the contribution of gel pores, capillary pores control the permeability leading to the conclusion that the Katz and Thompson theory could be used. However, for low porosity, they suggested that another model (the 
"GEM" model) considering the roles of both capillary and gel pores should be adopted, since in this case the capillary pores may be blocked by the hydration products so that the gel pores may play a more significant role in fluid transport. Given that the subject of this paper is foamed concrete, this suggests that the KatzThompson method is more likely to be appropriate and the validity of this assumption will be demonstrated later in this paper. Thus the aim of this paper is to investigate the pore structure characteristics, including the porosity and critical pore diameter, and their effect on the permeation characteristics, water absorption and permeability, of foamed concrete.

\section{Materials and mix proportions}

The materials used were:

i Ordinary Portland cement CEM I-52,5 N (3.15 S.G.) conforming to BS EN 197-1:2011 (BS EN 197-1, 2011)

ii Natural fine aggregate (sand) (2.65 S.G.) conforming to BS 882:1992 (BS 882, 1992), sieved to remove particles greater than $2.36 \mathrm{~mm}$, to help improve the flow characteristics and stability of the final product (ASTM C144, 1987; Jones and McCarthy, 2005)

iii Fresh, clean and potable water

iv Foam $\left(45 \mathrm{~kg} / \mathrm{m}^{3}\right)$ produced by blending a foaming agent, EABASSOC (1.05 S.G.), water and compressed air at predetermined proportions of 55/1 (water/ foaming agent) by volume in a foam generator, STONEFOAM-4.

Three quite different mixes of foamed concrete were made with nominal densities of 1300,1600 and 1900 $\mathrm{kg} / \mathrm{m}^{3}$. To achieve these target densities, the water cement ratios of these mixes were determined, by trials, ensuring the stability of the wet foamed concrete mix and also that the measured density was equal or nearly equal to the design density (Nambiar and Ramamurthy

Table 1 Mix proportions of selected foamed concrete mixes.

\begin{tabular}{cccc}
\hline & \multicolumn{3}{c}{ Mixes } \\
\cline { 2 - 4 } & FC3 & FC6 & FC9 \\
\hline Target density $\left(\mathrm{kg} / \mathrm{m}^{3}\right)$ & 1300 & 1600 & 1900 \\
Cement content $\left(\mathrm{kg} / \mathrm{m}^{3}\right)$ & 500 & 500 & 500 \\
W/C ratio & 0.475 & 0.5 & 0.525 \\
Water content $\left(\mathrm{kg} / \mathrm{m}^{3}\right)$ & 237.5 & 249.9 & 262.5 \\
Sand content $\left(\mathrm{kg} / \mathrm{m}^{3}\right)$ & 562 & 850 & 1137.5 \\
Foam $\left(\mathrm{L} / \mathrm{m}^{3}\right)$ & 424 & 295 & 166 \\
Foaming agent $\left(\mathrm{kg} / \mathrm{m}^{3}\right)$ & 0.35 & 0.24 & 0.13 \\
\hline
\end{tabular}

2007b; Nambiar and Ramamurthy 2008). The material required per $\mathrm{m}^{3}$ of the selected mixes was calculated using the absolute volume method. The required amount of foam was generated and added immediately to the base mix (sand-cement mix) and mixed in an ordinary mixer till the foam was uniformly distributed and incorporated into the mix (Nambiar and Ramamurthy 2007b). The fresh mix density was measured by weighing a preweighed container of known volume after filling it with foamed concrete. The mix proportions of the three foamed concrete mixes selected are given in Table $\mathbf{1}$.

\section{Experimental work}

\subsection{Porosity}

For the selected foamed concrete mixes, the apparent porosity was determined (see Table 2 ) by drying a 28 day old specimen $(100 \times 100 \times 70 \mathrm{~mm})$ at $100 \pm 5^{\circ} \mathrm{C}$ for 2 days, until constant mass, immersing it in water for 7 days (until constant weight) and then measuring its weight in air and water and applying the following equation:

$$
\phi_{a p p}=\frac{W_{s, a}-W_{d r y}}{W_{s, a}-W_{s, w}} \times 100
$$

where $\phi_{\text {app }}$ is the apparent porosity $(\%), W_{\mathrm{s}, \mathrm{a}}$ is the weight of a saturated sample in air, $W_{\mathrm{s}, \mathrm{w}}$ is the weight of the saturated sample in water and $W_{\text {dry }}$ is the weight of the oven-dried sample.

In addition, the total porosity was determined (see Table 2) using the vacuum saturation approach, as explained by (Kearsley and Wainwright 2002). Vacuum porosity measurements were conducted on 28-day old samples of $(100 \times 100 \times 70 \mathrm{~mm})$ that were dried at $100 \pm 5^{\circ} \mathrm{C}$ until a constant weight had been achieved and then placed in a desiccator under vacuum for at least 3 hours. After that, the desiccator was filled with deionised water to $30 \mathrm{~mm}$ above the samples and left under a vacuum pump for another 3 hours. The samples remained under water over night. Finally, the samples were weighed in air and water to calculate the total (vacuum determined) porosity $\left(\phi_{\text {vac }}\right)$ from Eq. 1 assuming them to now be fully saturated.

\subsection{Mercury intrusion porosimetry (MIP)}

The MIP test was also used to determine the total porosity (see Table 2), the characteristic length $\left(l_{\mathrm{c}}\right)$ and the conductivity factor (see Section 3.3) of the selected mixes. Mercury intrusion porosimetry characterizes a material porosity by applying a pressure to a sample

Table 2 Measured porosity results.

\begin{tabular}{c|c|c|c|ccc}
\hline \multirow{2}{*}{ Mixes } & \multirow{2}{*}{$\begin{array}{c}\text { Fesh Density } \\
\left(\mathrm{kg} / \mathrm{m}^{3}\right)\end{array}$} & $\begin{array}{c}\text { Dry Density } \\
\left(\mathrm{kg} / \mathrm{m}^{3}\right)\end{array}$ & $\begin{array}{c}\text { Design Foam Content }(\mathrm{Fv}) \\
(\% \text { of Vol.) }\end{array}$ & \multicolumn{3}{c}{ Porosity (\%) } \\
\cline { 5 - 7 } & 1305 & 1130 & 42.4 & Apparent $\phi_{\text {app }}$ & Total (Vacuum) $\phi_{\text {vac }}$ & MIP $\phi_{\text {MIP }}$ \\
\hline FC3 & 1610 & 1460 & 29.5 & 20.23 & 51.63 & 44.84 \\
\hline FC6 & 1890 & 1785 & 16.6 & 20.65 & 40.76 & 36.36 \\
\hline FC9 & 1890 & & & 28.73 & 28.01 \\
\hline
\end{tabular}


immersed in mercury. The pressure applied is inversely proportional to the size of the accessible pores that will be filled by mercury. The test was performed, to a maximum $414 \mathrm{MPa}$ (60000 psi) injection pressure, on fully dried $(10 \times 10 \times 20 \mathrm{~mm})$ specimens cut from three positions (top, centre and bottom) of samples previously tested for vacuum determined porosity and the applied pressure converted to pore diameter using the method described by Goual et al. (2006).

\subsection{Permeation characteristics}

The transport of aggressive liquids into concrete depends on its permeation characteristics (Nambiar and Ramamurthy 2007b). In this study, measurements of water absorption, the ease with which water can penetrate foamed concrete, and permeability, a measure of the flow of air under pressure, were carried out to determine the permeation characteristics.

\section{(1) Water absorption}

Absorption is usually measured by drying a specimen to a constant mass, immersing it in water and then measuring its mass increase as a percentage of dry mass (Neville 2011). Nambiar and Ramamurthy (2007b) reported that various procedures, different drying temperatures and/or immersion periods, have been adopted in measuring the water absorption resulting in widely different results. Examples are immersion in water for 24h (ASTM C796 1997), immersion for 7 days/till a constant mass (Kearsley and Wainwright 2001a) and adopting a vacuum saturation method. In this investigation, the ease with which water can penetrate foamed concrete was determined by measuring the water absorption on $(100 \times 100 \times 70 \mathrm{~mm})$ oven-dried specimens which had been cured under sealed conditions for 28 days and then immersed in water for 7 days (to a constant mass). The water absorption (to the nearest $0.5 \%$ ), $A b_{w}$, was expressed as a percentage of the volume of the whole specimen as follows, (ASTM C796 1997).

$$
A b_{w}=\frac{V_{w}}{V_{c}} \times 100
$$

$$
V_{w}=\frac{W_{w}-W_{d}}{\gamma_{w}}
$$

where $V_{\mathrm{w}}$ is the volume of water absorbed, $V_{\mathrm{c}}$ is the specimen volume, $W_{\mathrm{w}}$ is the weight of saturated specimen, $W_{\mathrm{d}}$ if the weight of oven dry specimen and $r_{\mathrm{w}}$ is the unit weight of water.

\section{(2) Permeability}

\section{-Constant head method}

Foamed concrete cylinders $(100 \times 140 \mathrm{~mm})$ were produced and then sealed-cured (wrapped in cling film) for 28 days. After that, $60 \mathrm{~mm}$ thick disks were cut from the middle of each cylinder, $30 \mathrm{~mm}$ above and below the central line thereby excluding regions of nonrepresentative porosity. These disks were dried at $105^{\circ} \mathrm{C}$ for 2 days to reach capillary dry conditions and tested at 30 days after mixing.

The air permeability coefficient, $k_{\text {air }}\left(\mathrm{m}^{2}\right)$, was calculated according to the Hangen-Poiseuille equation for laminar flow under steady-state conditions of a compressible fluid (Sanjuan and Munoz-Martialay 1996a);

$$
k_{\text {air }}=\frac{2 Q P_{o} L \mu}{A\left(P^{2}-P_{a}^{2}\right)}
$$

where; $Q$ is the air flow rate $\left(\mathrm{m}^{3} \cdot \mathrm{s}^{-1}\right), \mu$ is the air dynamic viscosity $\left(1.8 \times 10^{-5} \mathrm{~N} . \mathrm{s}^{-2}\right.$ at $\left.20^{\circ} \mathrm{C}\right), P$ is the absolute inlet pressure $\left(\mathrm{N} . \mathrm{m}^{-2}\right), P_{\mathrm{a}}$ and $P_{o}$ are outlet and measuring pressure, respectively (both are equal to the atmospheric pressure, $0.101 \mathrm{MPa}), A$ is the cross-section area $\left(0.00785 \mathrm{~m}^{2}\right)$ and $\mathrm{L}$ is the specimen thickness $(0.06$ $\mathrm{m})$.

The test steps of this method were as follows: a specimen was sealed in a hollow rubber cylinder for around 20 hours before the test to avoid the possibility of edge leakage. During testing, specified inlet air pressures $(0.6,0.5,0.4,0.3,0.2,0.15 \mathrm{MPa})$ was applied to the specimen in an apparatus. For each applied pressure an air flow $Q\left(\mathrm{~m}^{3} \mathrm{~s}^{-1}\right)$ were obtained by a flow meter connected at the end of the outlet tube, Fig. 1(a).

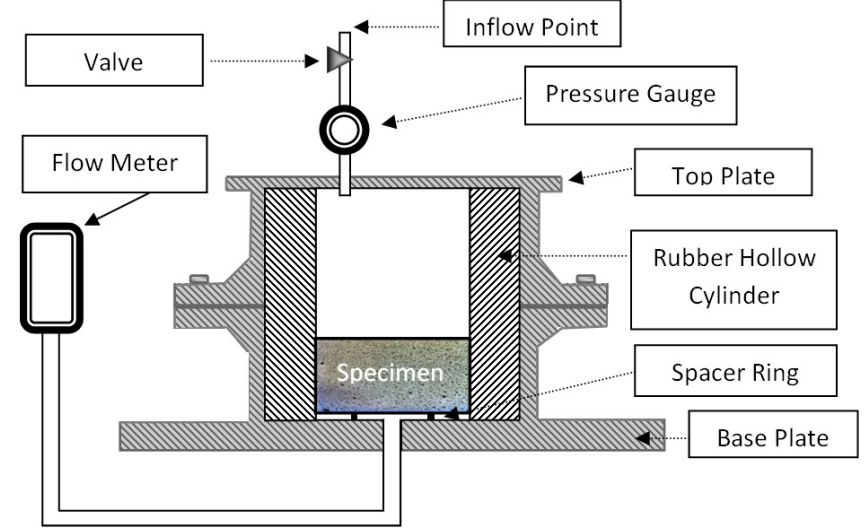

(a)

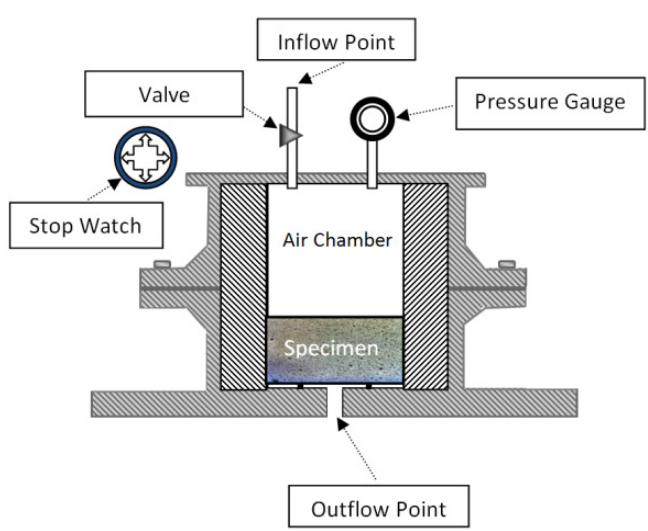

(b)

Fig. 1 (a) Schematic of a constant-pressure air permeameter (b) Schematic of a falling-pressure air permeameter. 


\section{- Falling head method}

Figure 1(b) describes the apparatus used for testing the air permeability of the selected mixes by the falling head method. The same size cylindrical specimen as used in the constant head method was used in this test by sealing it in a hollow rubber cylinder with a silicone sealant thereby forming an air chamber of $120 \mathrm{~mm}$ height. The method proposed by Li et al. (2004) was employed in which a large air pressure is applied to the top of the specimen and allowed to leak out through the specimen over time with the rate of pressure drop being monitored, 35 drops [from 603.3 (87.5 psi) to $17.2 \mathrm{kPa}$ (2.5 psi)].

From mathematical models based on Darcy's law for gases, Li et al. (2004) present an analytical solution for estimating air permeability using the test data obtained by a falling pressure method, as follows:

$$
k=-\frac{V Z \mu s}{A P_{a t m}}
$$

where: $k$ is the air permeability $\left(\mathrm{cm}^{2}\right), V$ is the air chamber volume $\left(\mathrm{cm}^{3}\right), Z$ is the specimen thickness $(\mathrm{cm}), \mu$ is the dynamic viscosity of air $\left(\mathrm{g} \mathrm{cm}^{-1} \mathrm{~s}^{-1}\right), A$ is the crosssection area $\left(\mathrm{cm}^{2}\right), P_{\mathrm{atm}}$ is the atmospheric pressure $(\mathrm{g}$ $\left.\mathrm{cm}^{-1} \mathrm{~s}^{2}\right)$ and $\mathrm{s}$ is the slope of the $\ln \left[c\left(P_{(t)}\right)^{-}\right.$ $\left.\left.P_{\text {atm }}\right) /\left(P_{(t)}+P_{\text {atm }}\right)\right]$ versus $t$ straight line. In addition, $P_{(t)}$ is the pressure at any time, $t$, and $c$ is a constant given by:

$$
c=\frac{P_{(0)}+P_{a t m}}{P_{(0)}-P_{a t m}}
$$

In addition, Li et al. (2004) derived a theoretical prediction of $\ln \left[\mathrm{c}\left(P_{(t)}-P_{\mathrm{atm}}\right) /\left(P_{(t)}+P_{\mathrm{atm}}\right)\right]$ versus $\mathrm{t}$ as follows;

$$
\ln \left(c \frac{P_{(t)}+P_{a t m}}{P_{(t)}-P_{a t m}}\right)=-\frac{A P_{a t m} k}{V Z \mu} t
$$

In this study, their method has been adopted to measure the air permeability of the selected mixes using the falling pressure method.

The validity of this analytical method is based on the assumption that $\delta<<1$ where $\delta$ is defined as:

$$
\delta=\frac{n_{a} \mu Z^{2}}{k P_{m}} \times \frac{P(t)}{P^{2}(t)-P_{a t m}^{2}} \times\left|\frac{d P}{d t}\right|
$$

$n_{\mathrm{a}}$ is the air-filled porosity and $P_{\mathrm{m}}$ is the main air pressure defined as the average of the minimum and maximum pressure in the test.

Based on Eq. 5, Li et al. (2004) derived a theoretical prediction for the pressure $P_{(t)}$ at any time $t>0$, as follows:

$$
P_{(t)}=\frac{\left(c+e^{-s t}\right) P_{a t m}}{c-e^{-s t}}
$$

- Calculated permeability

Many models and theories have been developed to predict the permeability of a porous medium by linking its transport properties to microstructural parameters such as porosity, pore surface area and critical pore diameter (Yen 2007). The approach used in this study is that of Katz and Thompson (Katz and Thompson 1986), which is particularly suitable for the permeability of a porous material, giving $k$, in units of $\mathrm{m}^{2}$, as follows:

$$
k=\frac{1}{266} \cdot \frac{\sigma}{\sigma_{o}} l c^{2}
$$

where $\sigma$ is the electrical conductivity of the saturated porous material $(\mathrm{S} / \mathrm{m})$ (Siemens per metre), $\sigma_{o}$ is the conductivity of the solution in the pores $(\mathrm{S} / \mathrm{m})\left(1.02 * 10^{6}\right.$ $\mathrm{S} / \mathrm{m}$ at $20^{\circ} \mathrm{C}$ for mercury) and $l_{\mathrm{c}}$ is the characteristic length scale of the material. Katz and Thompson reported that, as can be seen from Eq. 10, the conductivity term reflects the connectedness of the pore space, whereas the length term sets the scale for the permeability.

However, it has been shown that $l_{\mathrm{c}}$, the maximum continuous length scale or the critical pore diameter, can be generated from an MIP experiment (Christensen et al. 1996; Katz and Thompson 1986). In this study, the values of conductivity factor $\left(\sigma / \sigma_{o}\right)$ were also obtained from MIP data and were not computed directly from electrical measurements.

\section{Results and discussion}

\subsection{Porosity}

From Table 2, for all selected mixes, it can be seen that the apparent porosity at normal condition is lower than that determined by the vacuum saturation method. This difference shows that the entrained pores (air-voids) are not taking part in the conventional water absorption as they are not interconnected, see Fig. 2, the contribution to water absorption being only by the capillary pores, which depend on the paste content (Nambiar and Ramamurthy 2006; Nambiar and Ramamurthy 2007b). Because the MIP technique only determines pore diameters up to $400 \mu \mathrm{m}$ and because the SEM data, Fig. 2, shows that many pores were larger than $400 \mu \mathrm{m}$, the porosity obtained from MIP was lower than the total porosity as measured by vacuum saturation for all mixes. The real total porosity of foamed concrete is the sum of the entrapped air voids (artificial air voids) and the voids within the paste, gel and capillary pores (Kearsley and Wainwright 2002; Kearsley and Wainwright 2001b; Nambiar and Ramamurthy 2007b). Therefore and because pore diameters from $4 \mathrm{~nm}$ can be determined by the MIP technique, the effect of the variation of water content will be taken into account within the total porosities values and this will not affect the meaning of the final conclusions in any way.

where $\mathrm{s}$ is as in Eq. 5 . 

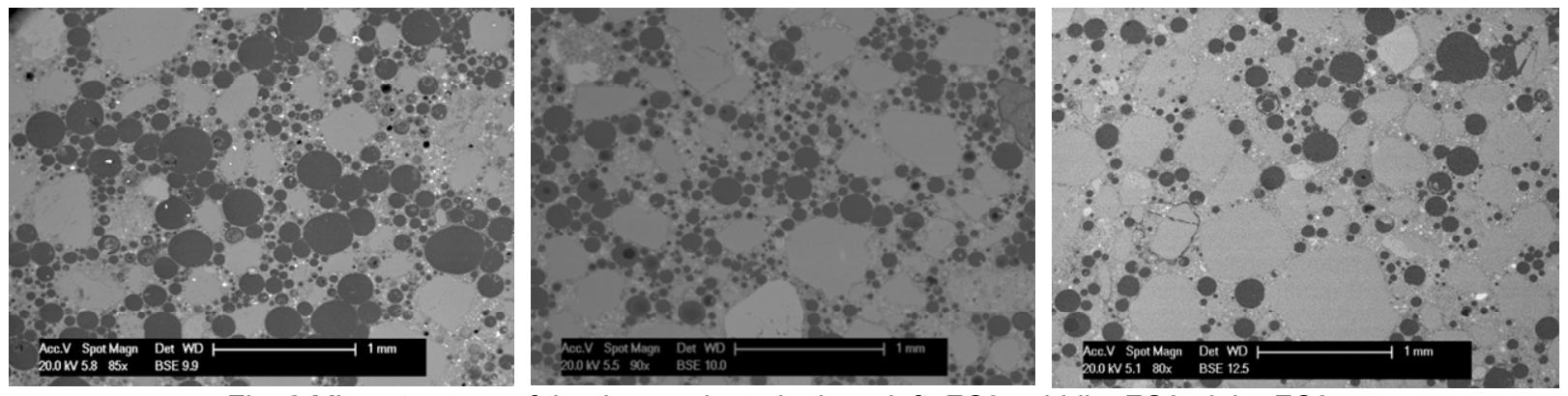

Fig. 2 Microstructure of the three selected mixes; left: FC3; middle: FC6; right: FC9.

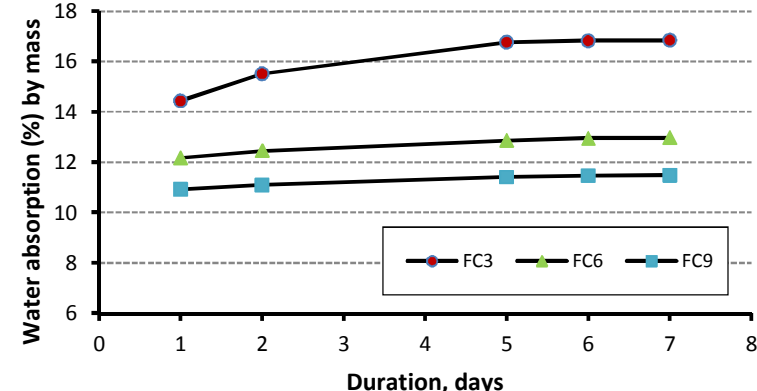

(a)

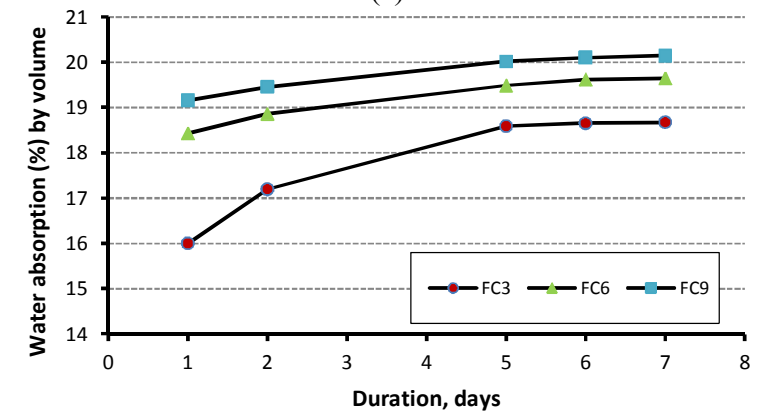

(b)

Fig. 3 Variation in water absorption with time of the selected mixes (a) by mass; (b) by volume.

\subsection{Water absorption}

Although absorption of normal concrete is usually expressed as the increase in mass as a percentage of oven dry mass, for foamed concrete it is here expressed as a percentage of volume to avoid misleading results because of the large differences in density between the three mixes tested (Kearsley and Wainwright 2001b; Nambiar and Ramamurthy, 2006; Nambiar and Ramamurthy, 2007b). Fig. 3 (a, b) shows the variation in water absorption due to simple immersion with time for foamed concrete, respectively $\%$ by mass and $\%$ by volume. An important observation is that the water absorption of foamed concrete, represented as a percentage by mass, increases with a reduction in density (Kearsley and Wainwright 2001b), while when it is represented as a percentage of volume, it is seen that it is lower at lower densities (Nambiar and Ramamurthy 2006; Nambiar and Ramamurthy 2007b), see Fig. 4.

Although the total porosity clearly increases with a reduction in density of foamed concrete (increase of the foam volume), the water absorption ( $\%$ by volume) ex-

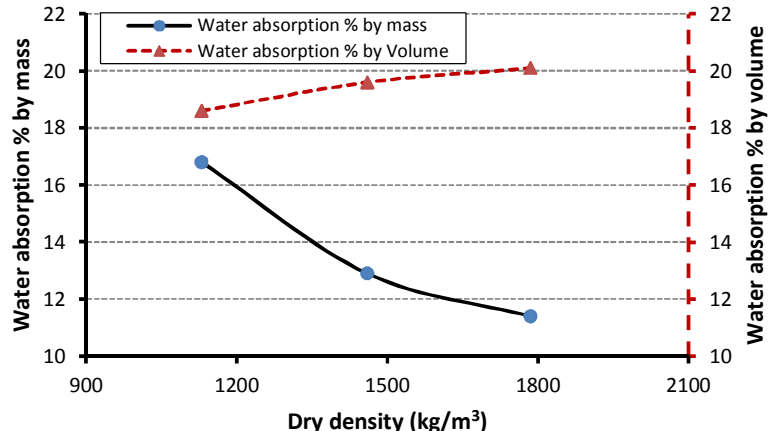

Fig. 4 Water absorption percent of mass and volume as a function of dry density.

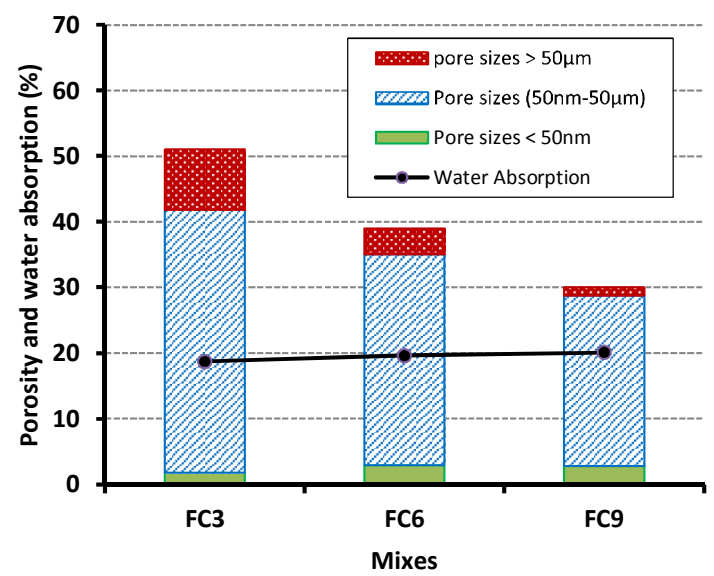

Fig. 5 The distribution of microcapillaries, macrocapillaries and pores as a porosity (\%) and the water absorption percent of volume.

hibits a reduction, Fig. 5. This implies that not all the artificial pores are taking part in water absorption, indicating that most of them are not interconnected. From Fig. 5, it can be seen that as the foam volume increases the volume of entrained air pores increases reducing the paste content and causing a reduction in the volume of capillary pores and thus resulting in a decreasing trend of water absorption (Nambiar and Ramamurthy 2007b). This is supported by another study on properties of foamed concrete (Nambiar and Ramamurthy 2006), where it was shown that some mixes without foam showed higher water absorption than foamed concrete mixes. Thus, the water absorption of mixes with and without foam is mainly influenced by the paste phase. 


\subsection{Air permeability}

In this study, the air permeability was measured by adopting the constant and falling head methods and was calculated by applying the Katz and Thompson equation The results are listed in Table 3. In terms of the constant head method, the air permeability coefficient, $\mathrm{k}_{\text {air }}\left(\mathrm{m}^{2}\right)$, was obtained by multiplying the slope of the straight line relationship between the air flow rate and the pressure difference $\left(P^{2}-P_{\mathrm{a}}{ }^{2}\right)$ by $\left(2 P_{o} L \mu\right)$, see Eq. 4 .

With regard to the falling head method, Fig. 6 shows how the pressure function $\ln \left[\mathrm{c}\left(P_{(t)}-P_{\mathrm{atm}}\right) /\left(P_{(t)}+P_{\mathrm{atm}}\right)\right]$ changes with time for the average of three repeated tests for the FC9 mix and that the theoretical prediction (Eq. 7) gives a satisfactory match. By using the slope of the straight line, the air permeability of the sample was estimated based on Eq. 5. In addition, by using this slope and applying Eq. 9, a theoretical prediction of the pressure at any time can be drawn, Fig. 7. From this figure,

Table 3 Measured and calculated permeability results.

\begin{tabular}{ccccc}
\hline \multirow{2}{*}{ Mixes } & $\begin{array}{c}\text { Dry Density } \\
\left(\mathrm{kg} / \mathrm{m}^{3}\right)\end{array}$ & \multicolumn{3}{c}{ Permeability $\left(\mathrm{m}^{2}\right)$} \\
\cline { 3 - 4 } & & Constant & Falling & Katz \\
\cline { 3 - 4 } \cline { 3 - 4 } & 1135 & $5.58 * 10^{-14}$ & $6.4 * 10^{-14}$ & $6.8 * 10^{-14}$ \\
\hline FC3 & 1455 & $1.1 * 10^{-15}$ & $1.25 * 10^{-15}$ & $1.22 * 10^{-15}$ \\
\hline FC6 & 1790 & $2.89 * 10^{-16}$ & $5.1 * 10^{-16}$ & $3.92 * 10^{-16}$ \\
\hline FC9 & $1790^{2}$ & & & \\
\hline
\end{tabular}

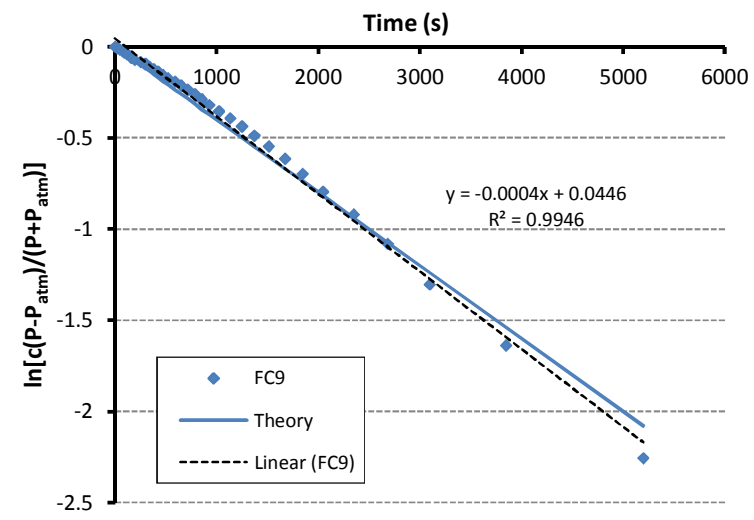

Fig. 6 In $\left[\mathrm{c}\left(P-P_{\text {atm }}\right) /\left(P+P_{\text {atm }}\right)\right]$ versus time test data for FC9 and its linear analytical prediction by Eq. (7).

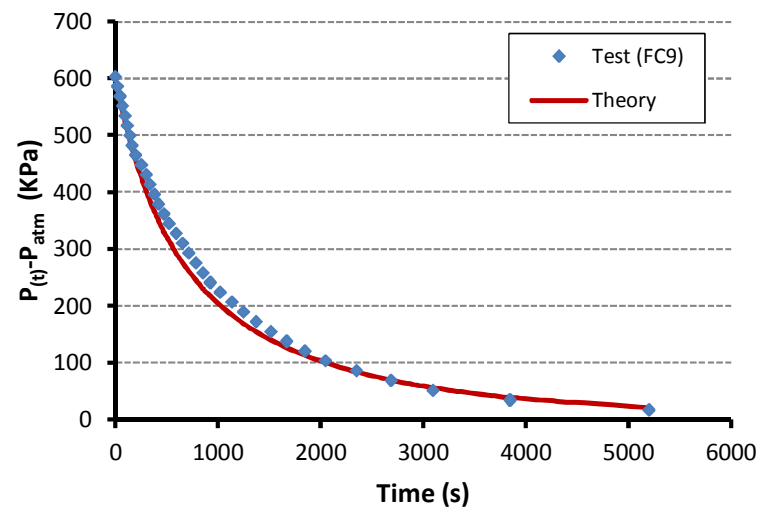

Fig. $7\left(P_{(t)}-P_{\text {atm }}\right)$ versus time test data for FC9 and its linear analytical prediction by Eq. (9). it is observed that there is a good fit between the observed data and the theoretical prediction. It should be noted that the validity of this method has been checked by using Eq. 8 obtaining values of $\delta$ between 0.032 for FC9 and 0.065 for FC3. Thus the condition $\delta<<1$ of Eq. 8 is satisfied.

From the MIP test data, the conductivity factor $\left(\sigma / \sigma_{o}\right)$ and critical pore diameter $\left(l_{\mathrm{c}}\right)$ were obtained. The $\sigma$ or $\sigma_{o}$ is the proportionality constant between electrical current per unit cross-sectional area $(i / A)$ and the gradient of the electrical potential $V[i / A=\sigma \nabla V]$ according to Ohm's law (Friedman and Seaton 1998). Meanwile, as explained in Section 1 that the $l_{\mathrm{c}}$ is defined as the smallest size of pores that remain interconnected. As it is practically impossible to determine this size directly, an indirect assessment is usually achieved by the MIP technique. The $l_{\mathrm{c}}$ is taken to be the pore size at which the mercury enter the pores at its fastest rate as this must represent the point at which the pores become largely interconnected (El-Dieb and Hooton 1994). This size corresponds to the steepest part of the plot of cumulative intruded volume versus pore diameter (also the pore size at which the $\mathrm{dV} / \mathrm{d}(\log \mathrm{D})$ versus $\mathrm{D}$ plot reaches its maximum value), see Fig. 8, is interpreted as the critical pore diameter $\left(l_{\mathrm{c}}\right)$, being $9.89,1.93$ and $1.27 \mu \mathrm{m}$ for FC3, FC6 and FC9, respectively (Fig. 9). While the conductivity factor, respectively, was $0.159,0.085$ and 0.055 for FC3, FC6 and FC9. These figures were then inserted into the Katz and Thompson equation (Eq. 10).

Figure 10 shows a comparsion between the measured and calculated permeability values for this study and
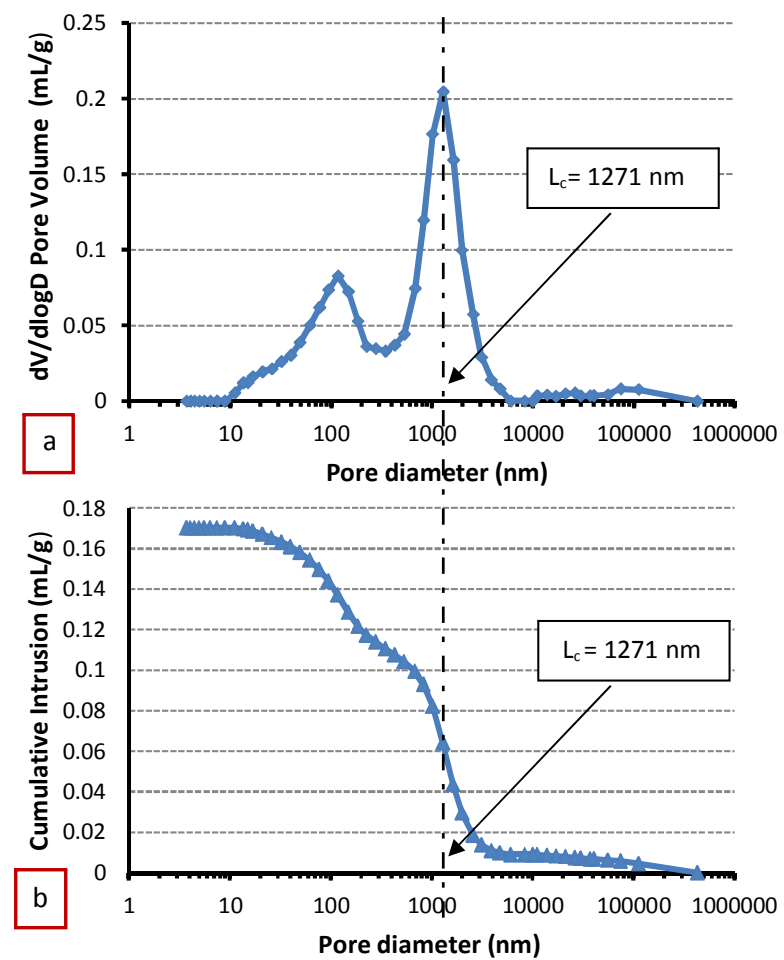

Fig. 8 (a) Critical pore diameter of FC9 mix; (b) the variation of cumulative intrusion mercury volume of FC9 mix. 


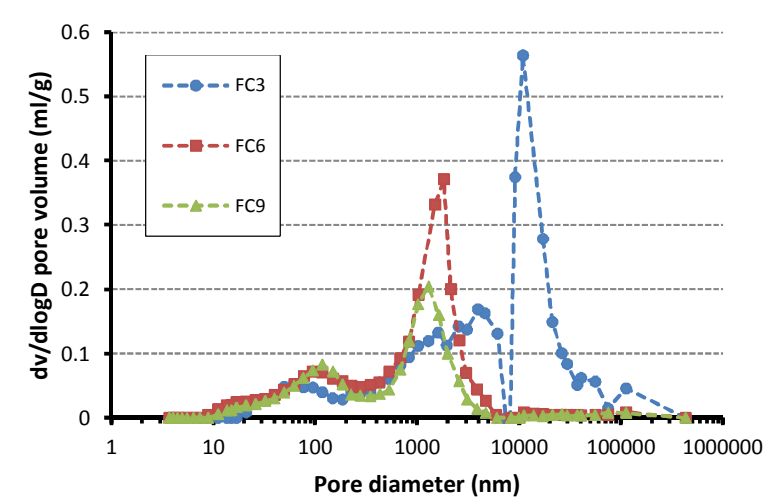

Fig. 9 Critical pore diameter of the three selected foamed concrete.

studies from the literature. It can be seen that applying the Katz and Thompson equation to foamed concrete (this study) or very porous cement pastes (Christensen et al. 1996) yielded a good correlation with the experimental values. Howerver, for cementitious materials with low porosity, El-Dieb and Hooton (1994) concluded that the Katz and Thompson equation is not suitable (large difference btween the experimental and calculated results). Halamickova et al. (1995), found that the Katz and Thompson equation provided a good permeability estimation at $\mathrm{w} / \mathrm{c}=0.5$ but the predicted permeabilities were overestimated at $\mathrm{w} / \mathrm{c}=0.4$, see Fig. 10, suggesting that this relationship may be applied better with interconnected capillary systems rather than systems where the gel pores dominate the transport. In addition, Fig. 10 shows that the general effective media model (GEM) is not suitable for a porous material (this study) but it appears to be a suitable tool for cementitious materials with low porosity (Cui and Cahyadi, 2001). Note that for this study, the procedure employing the GEM model, as proposed by Cui and Cahyadi (2001), was also used to calculate the foamed concrete permeability. Capillary porosities (a difference between the total porosity and the added foam) of $9.23 \%$, $11.23 \%$ and $12.13 \%$ for FC3, FC6 and FC9, respectively were adopted. It can be seen that use of this GEM model was not as successful in predicting permeability as the Katz and Thompson approach for the foamed concrete.

\subsection{Permeability and pore characteristics}

Figure 11 demonstates that there are inverse relationships for both porosity and permeability with dry density leading to a positive relationship between porosity and permeability, Fig. 12. From these two figures, it is obvious that the air permeability coefficient decreases with increase in the density or decrease in the amount of added foam (porosity). Moreover, by decreasing the porosity from about $51 \%$ for FC3 to $29 \%$ for FC9 the

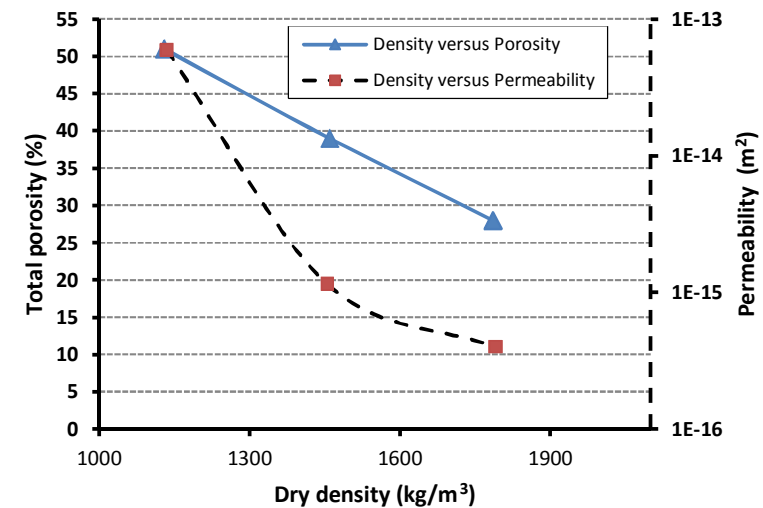

Fig. 11 Porosity and permeability as a function of dry density.

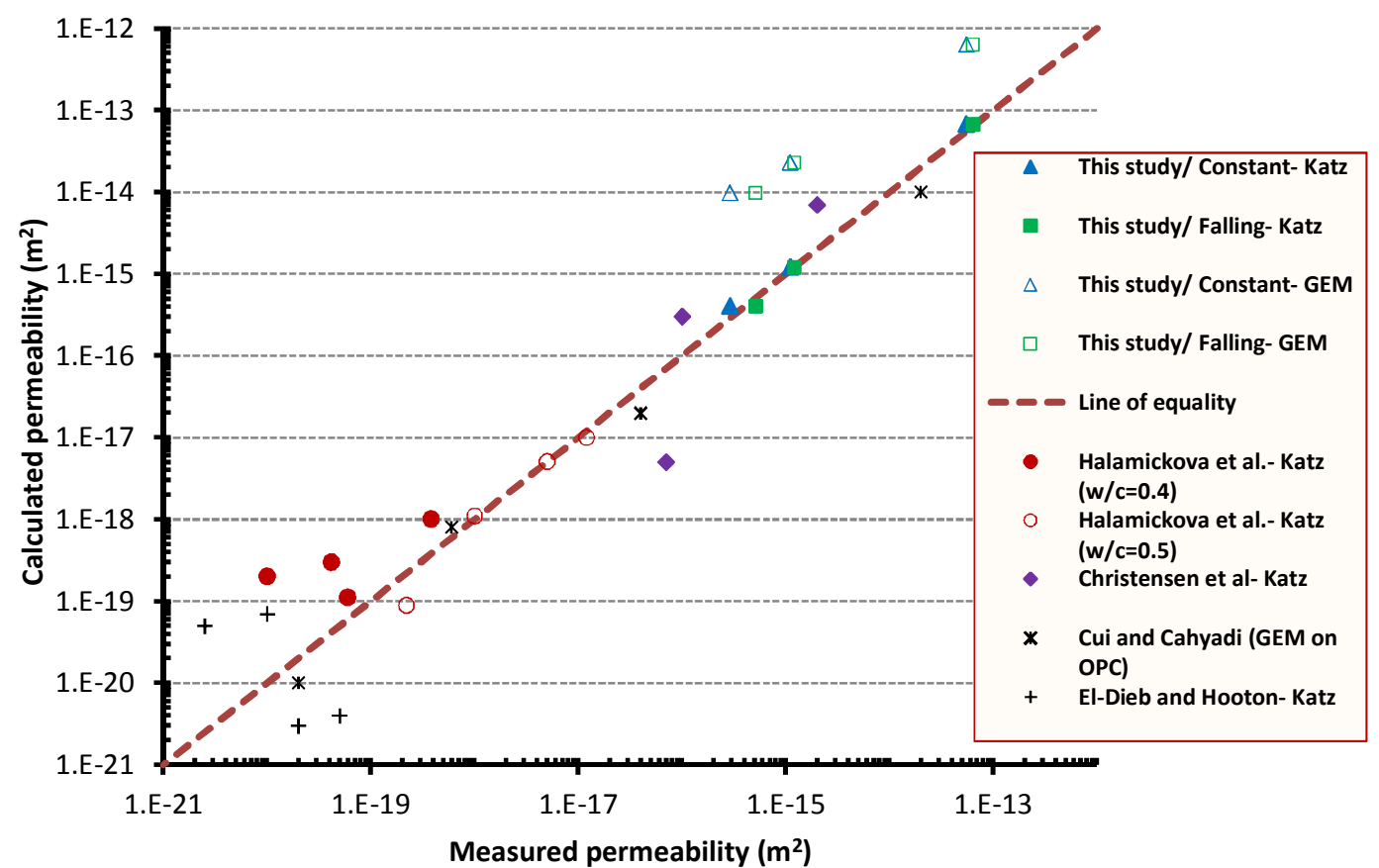

Fig. 10 Comparison between the measured and calculated permeability values. 


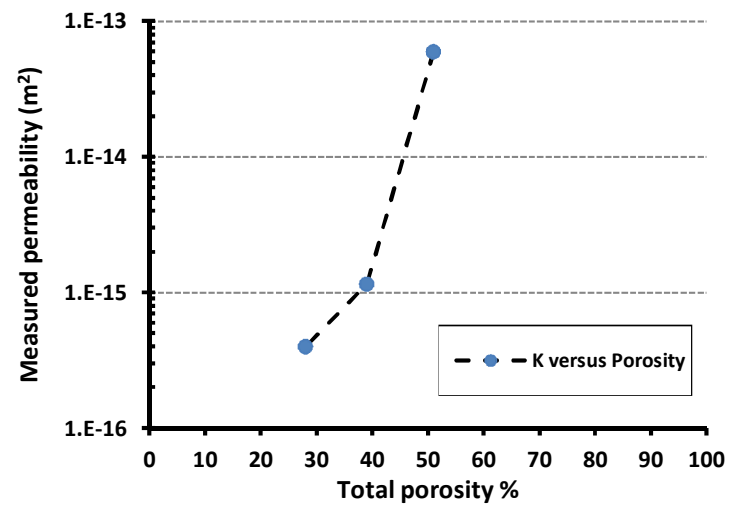

Fig. 12 Air permeability versus porosity of the selected mixes.

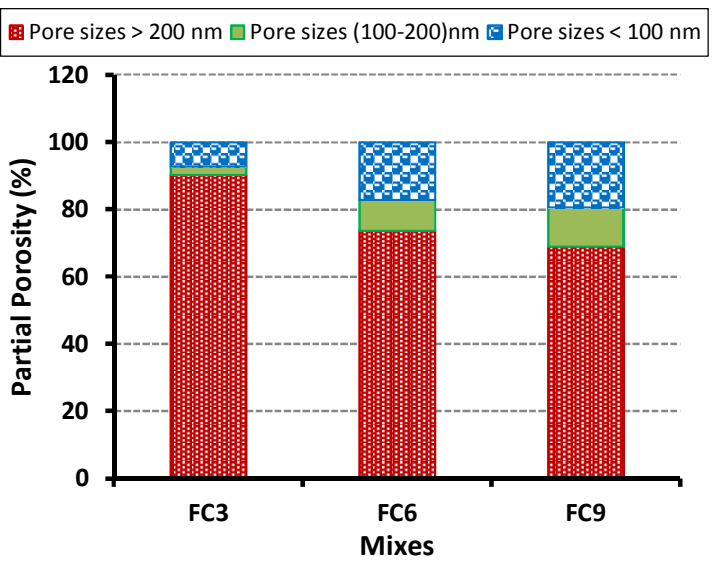

Fig. 13 The distribution of fine capillary, large capillary and large pores as a partial porosity (\%).

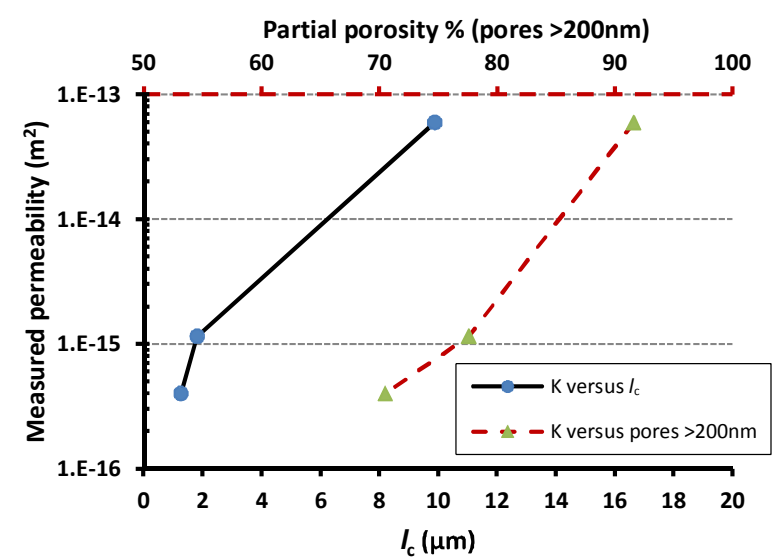

Fig. 14 The relationships between measured permeability and both critical pore diameter $\left(I_{\mathrm{c}}\right)$ and partial porosity (pores $>200 \mathrm{~nm}$ ).

permeability decreases by about 200 times indicating a highly non-linear relationship between them. This means that not only the volume of voids but also their connectivity (usually higher with increased added foam) are controlling the air permeability. In order to determine the distribution of pores and their relationship to permeability from the intrusion curves (determined by the MIP test) and after adding the difference in voids volume between the vacuum and MIP tests (voids of size higher than $400 \mu \mathrm{m})$, the porosity in a specified range of pore sizes was normalized with the total porosity into three ranges of pore width, $>200,100-200$, and $<100 \mathrm{~nm}$, Fig. 13. The first range is mainly related to the permeability of cementitious material (Akcay 2007; Yang et al. 2006). From Fig. 13, it is obvious that the pore range with diameter $>200 \mathrm{~nm}$ decreases with increase in the density of foamed concrete resulting in decreasing permeability, Fig. 14. Noting that these partial porosities do not represent the actual values since by using the MIP technique most of pores are measured smaller that in reality (Diamond 2000). However the partial porosities provide useful comparative indices about the pore system of the selected mixes. In addition, since the critical pore diameter $\left(l_{\mathrm{c}}\right)$ represents the grouping of the largest fraction of interconnected pores (Yang et al. 2006), it can be expected to influence the transport properties such as permeability and from Fig. 14, it can be seen that there is a positive relationship between the critical pore diameter and the permeability of foamed concrete.

\section{Conclusions}

From the tests carried out on foamed concrete and based on the above results and discussion, the following conclusions can be drawn:

(1) The vacuum saturation method provides the most appropriate means of accurately assessing the porosity for foamed concrete.

(2) Although porosity increases with a reduction in density of foamed concrete (due to an increase of the foam volume), the water absorption ( $\%$ by volume) exhibits a reduction. Therefore, many of the artificial pores due to the added foam are not taking part in water absorption, indicating that many of them are not interconnected.

(3) There is a good agreement between the results obtained from the constant and falling head air permeability test methods on foamed concrete.

(4) The predictive permeability equation derived by Katz and Thompson best fits the air permeability results determined in this investigation.

(5) Both the critical pore diameter and the pore range with diameter $>200 \mathrm{~nm}$ decrease with increase in the density and there is a strong positive relationship between them and the permeability of foamed concrete, confirming the suggestion of (Akçay, 2007) that these are the pore sizes which control permeability.

(6) The observation that water absorption decreases with added (foam) voids, suggests that these voids may not lead to an increase in water transport through foamed concrete. This is worthy of future investigation.

\section{Acknowledgements}

The authors would like to acknowledge the support of 
the Higher Committee for Education Development in Iraq (HCED) for the research scholarship enabling this work to be conducted as part of a larger reseach project. The authors also wish to thank Dr Daniel Wells (E-A-B Associates Company, UK) for providing the foaming agent and Mr Frank Göller (Kao Chemical GmbH, Germany) for providing the superplasticizer. Finally, the valuable help and comments of $\mathrm{Mr}$ Keith Dinsdale (University of Nottingham) during the MIP test and $\mathrm{Mr}$ Martin Roe (University of Nottingham) during the SEM test are gratefully acknowledged.

\section{References}

Akçay, B., (2007). "Effects of lightweight aggregates on autogenous deformation and fracture of high performance concrete." Civil Engineering, Istanbul Technical University.

Alshamsi, A. M. and Imran, H. D., (2002). "Development of a permeability apparatus for concrete and mortar." Cement and Concrete Research, 32(6), 923-929.

ASTM C144, (1987). "Standard Specification for Aggregate for Masonry Mortar." American Society for Testing and Materials.

ASTM C796, (1997). "Standard test method for foaming agent for use in producing cellular concrete using preformed foam." American Society for Testing and Materials.

BS 882, (1992). "Specification for aggregates from natural sources for concrete." British Standards Institution, London.

BS EN 197-1, (2011). "Cement-Part 1: Composition, Specifications and Conformity Criteria for Common Cements."

Christensen, B. J., Mason, T. O. and Jennings, H. M., (1996). "Comparison of measured and calculated permeabilities for hardened cement pastes." Cement and Concrete Research, 26(9), 1325-1334.

Cui, L. and Cahyadi, J. H., (2001). "Permeability and pore structure of OPC paste." Cement and Concrete Research, 31(2), 277-282.

Diamond, S., (2000). "Mercury porosimetry: An inappropriate method for the measurement of pore size distributions in cement-based materials." Cement and Concrete Research, 30(10), 1517-1525.

El-Dieb, A. S. and Hooton, R. D., (1994). "Evaluation of the Katz-Thompson model for estimating the water permeability of cement-based materials from mercury intrusion porosimetry data." Cement and Concrete Research, 24(3), 443-455.

Friedman, S. P. and Seaton, N. A., (1998). "Critical path analysis of the relationship between permeability and electrical conductivity of three-dimensional pore networks." Water Resources Research, 34(7), 17031710 .

Goual, M., Bali, A., de Barquin, F., Dheilly, R. and Queneudec, M., (2006). "Isothermal moisture properties of clayey cellular concretes elaborated from clayey waste, cement and aluminium powder." Cement and Concrete Research, 36(9), 1768-1776.

Halamickova, P., Detwiler, R. J., Bentz, D. P. and Garboczi, E. J., (1995). "Water permeability and chloride ion diffusion in portland cement mortars: Relationship to sand content and critical pore diameter." Cement and Concrete Research, 25(4), 790-802.

Jitchaiyaphum, K., Sinsiri, T. and Chindaprasirt, P., (2011). "Cellular lightweight concrete containing pozzolan materials.” Procedia Engineering, 14, 11571164.

Jones, M. and McCarthy, A., (2005). "Preliminary views on the potential of foamed concrete as a structural material." Magazine of Concrete Research, 57(1), 2131.

Katz, A. and Thompson, A., (1986). "Quantitative prediction of permeability in porous rock." Physical review. B, Condensed Matter, 34(11), 8179-8181.

Kearsley, E. and Wainwright, P., (2001a). "Porosity and permeability of foamed concrete." Cement and Concrete Research, 31(5), 805-812.

Kearsley, E. and Wainwright, P., (2002). "The effect of porosity on the strength of foamed concrete." Cement and Concrete Research, 32(2), 233-239.

Kearsley, E. P. and Wainwright, P. J., (2001b). "Porosity and permeability of foamed concrete." Cement and Concrete Research, 31(5), 805-812.

Li, H., Jiao, J. J. and Luk, M., (2004). "A fallingpressure method for measuring air permeability of asphalt in laboratory." Journal of Hydrology, 286(1), 69-77.

Nambiar, E. and Ramamurthy, K., (2006). "Influence of filler type on the properties of foam concrete." Cement and Concrete Composites, 28(5), 475-480.

Nambiar, E. and Ramamurthy, K., (2007a). "Air - void characterisation of foam concrete." Cement and Concrete Research, 37(2), 221-230.

Nambiar, E. K. K. and Ramamurthy, K., (2007b). "Sorption characteristics of foam concrete." Cement and Concrete Research, 37(9), 1341-1347.

Nambiar, E. K. K. and Ramamurthy, K., (2008). "Fresh state characteristics of foam concrete." Journal of Materials in Civil Engineering, 20(2), 111-114.

Neville, A. M., (2011). "Properties of concrete." 5th ed. Pearson Education Limited, London

Othuman, M. A. and Wang, Y. C., (2011). "Elevatedtemperature thermal properties of lightweight foamed concrete." Construction and Building Materials, 25(2), 705-716.

Ramamurthy, K., Nambiar, E. K. K. and Indu Siva Ranjani, G., (2009). "A classification of studies on properties of foam concrete." Cement and Concrete Composites, 31(6), 388-396.

Sanjuan, M. and Munoz-Martialay, R., (1996a). "Modelling of the concrete air permeability evolution over time." Materials Letters, 27(4), 269-272.

Sanjuan, M. A. and Munoz-Martialay, R., (1996b). 
"Influence of the water/cement ratio on the air permeability of concrete." Journal of Materials Science, 31(11), 2829-2832.

Yang, C., Cho, S. and Wang, L., (2006). "The relationship between pore structure and chloride diffusivity from ponding test in cement-based materials." Materials Chemistry and Physics, 100(2), 203-210.
Yen, L. B., (2007). "Study of water ingress into foamed concrete." Department of Civil Engineernig, National University of Singapore.

Yu, X. G., Luo, S. S., Gao, Y. N., Wang, H. F., Li, Y. X., Wei, Y. R. and Wang, X. J., (2011). "Pore structure and microstructure of foam concrete." Advanced Materials Research, 177, 530-532. 